\title{
XXXV. On the inorganic constituents of organic bodies
}

\section{H. Rose}

To cite this article: $\mathrm{H}$. Rose (1849) XXXV. On the inorganic constituents of organic bodies , Philosophical Magazine Series 3, 35:236, 271-288, DOI: 10.1080/14786444908646348

To link to this article: http://dx.doi.org/10.1080/14786444908646348

曲 Published online: 30 Apr 2009.

Submit your article to this journal ๘

Џll Article views: 2

Q View related articles $\sqsubset$ 
XXXV. On the Inorganic Constituents of Organic Bodies. By H. Rose, Professor of Chemistry in the University of Berlin.

[Continued from p. 187.]

\section{APPENDIX IX.}

Examination of the Inorganic Constituents of the Flesh of the Horse. By M. Weber.

THE flesh consisted of the muscles of the fore-leg of a lean 1 horse, immediately after the animal was killed, and completely freed from blood by the injection of water into the brachial artery until it escaped from the veins in a colourless state; it was then dried and carbonized.

The residue of the aqueous extract was perfectly free from carbonic acid, and consisted of-

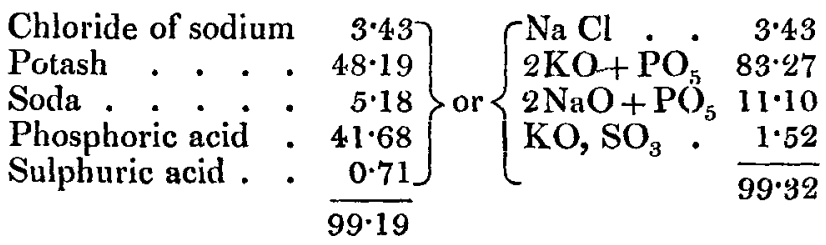

The muriatic extract consisted of-

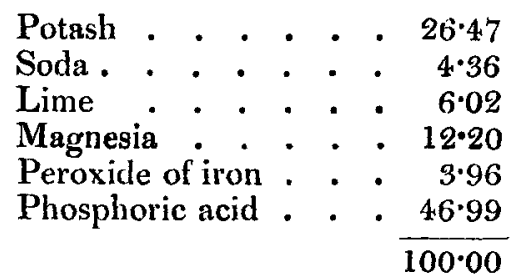

Assuming that the phosphoric acid forms pyrophosphates with the bases, we obtain the following calculated result:-

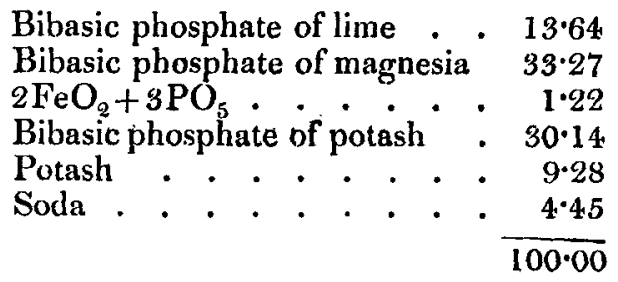

If, however, we admit that both the alkalies and the earths, excluding the magnesia, form $c$-phosphates, we obtain the following result :- 


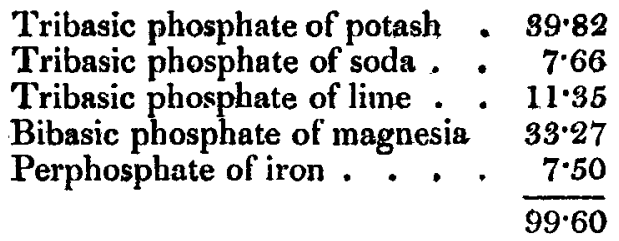

The amount of phosphoric acid required by calculation is 46.6 l per cent.; that found by analysis amounts to 46.99 per cent.

Residuary carbonized mass. - The ash of this consisted of-

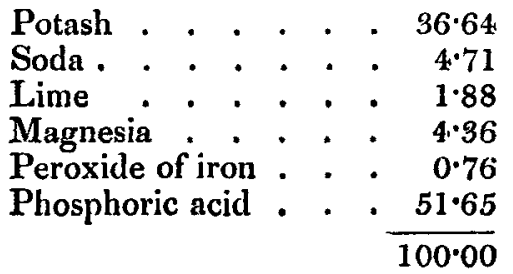

The precipitate thrown down by ammonia from the muriatic solution of this ash, after having been heated to redness, consisted of $2 \mathrm{CaO}, \mathrm{PO}_{5}+2 \mathrm{MgO}, \mathrm{PO}_{5}+\mathrm{Fe}_{2} \mathrm{O}_{3}$. The phosphoric acid required by this formula amounts to 9.87 per cent.; analysis gave exactly this quantity. 'The remaining $41 \cdot 79$ per cent. of phosphoric acid were neither wholly combined with the alkalies as pyrophosphates, nor as metaphosphates. The phosphoric acid is too large in quantity for the former case, and too small for the latter.

The relative amounts of ash in the flesh were as follows:-

Extracted by water . . . . . . . 42.81

Extracted by muriatic acid . . . . . 17*48

Ash of the remaining carbonaceous mass $39 \cdot 71$

$\overline{100 \cdot 00}$

The amount of the whole of the inorganic constituents of the flesh was-

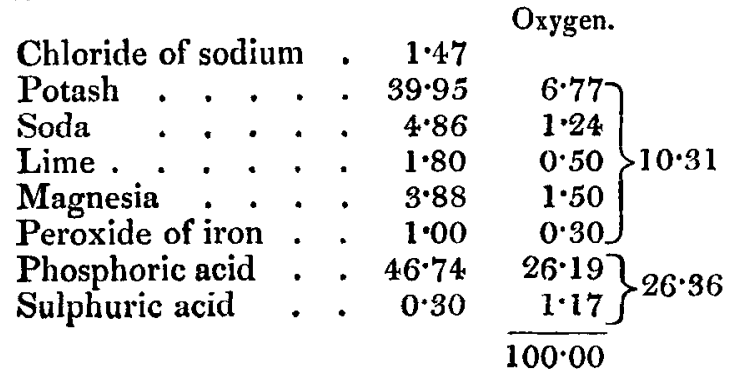


The proportion of oxygen in the bases to that of the phosphoric acid was as $2: 5, i$.e the salts were pyrophosphates; and in this respect this ash has some analogy with that of wheat, which, however, contains far more alkaline chlorides.

Thus water and muriatic acid principally extract alkaline phosphates from carbonized flesh, and alkaline chlorides and carbonates from carbonized blood. The muriatic extract of the blood contains altogether so few constituents, that we may suppose they are only those which had previously resisted the solvent action of water, or were formed from the anoxidic portion of the blood by the imperfect exclusion of the air during its carbonization.

If so, and we admit that the alkaline chlorides and carbonates do not belong to those constituents of the blood, the inorganic portions of which consist of phosphates in an oxidized and unoxidized state, these constituents of the blood would contain the phosphates in a perfectly deoxidized state. Such are probably the proteine substances of the blood, which would then differ from those of the flesh, by the former being anoxidic and the latter meroxidic substances. Probably in future we must only call those substances anoxidic, meroxidic, and teleoxidic, the inorganic constituents of which consist principally of phosphates in a deoxidized, partly oxidized, and perfectly oxidized state. The blood will then be an anoxidic, and the flesh a meroxidic substance.

\section{Appendix $\mathrm{X}$. and $\mathrm{XI}$.}

Analysis of the Ashes of Human Faces and Urine. By M. Fleitmann.

Although a single analysis of the ash of the freces, without regard to the diet, can be of but little physiological importance, inasmuch as it must depend greatly upon the nature of the food consumed and upon the mode of life of the individual, yet a comparative examination of the inorganic constituents of the fæces and urine may afford us instructive conclusions regarding the quantities excreted in the same period of tine. Such a comparison had not previously, I believe, been made, and as we shall see, has yielded a remarkable result. For this purpose the freces and urine of a young man, aged 20, were carefully collected during four days. During this period his diet was very moderate, consisting principally of meat, and as little vegetable matter as possible. He drink no spirituous liquids, and little liquid of any kind during the period, but he took much corporeal exercise.

Freces.-When dried at $212^{\circ} \mathrm{F}$. they weighed only $104 \cdot 10$ grms. They were carbonized as usual.

Phil. Mag. S. 3. Vol, 35. No. 236. Oct. 1849. 
Aqueous extract.-On evaporation to dryness it left a residue of $1.933 \mathrm{grm}$, consisting of-

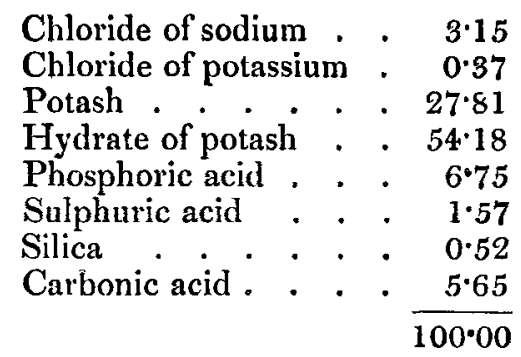

The large amount of hydrate of potash was produced by the action of the carbon upon the alkaline carbonate. 'These constituents correspond to the following salts:-

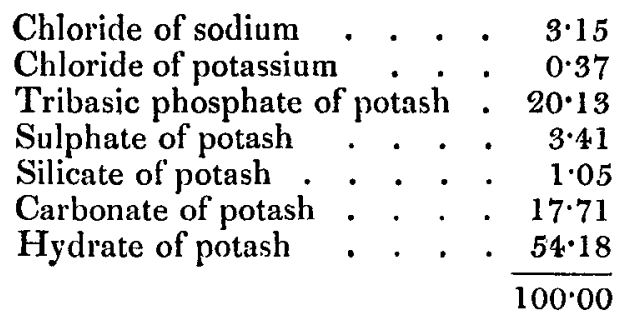

Muriatic extract.-This left 6.493 grms. of residue, consisting of -

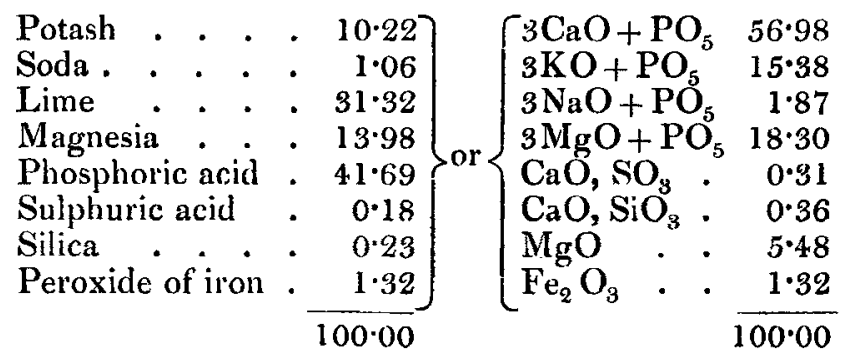

The magnesia must have existed in the carbonized mass in the form of carbonate.

Residuary carbonaceous mass.-This was considerable, and consisted principally of sand, part of which existed as such in the fæces, and even in the food; part must have been swallowed in the form of clust during the exercise taken by the subject of the experiment in the fields near Berlin. The residue weighed 1.996 grm., and consisted of- 


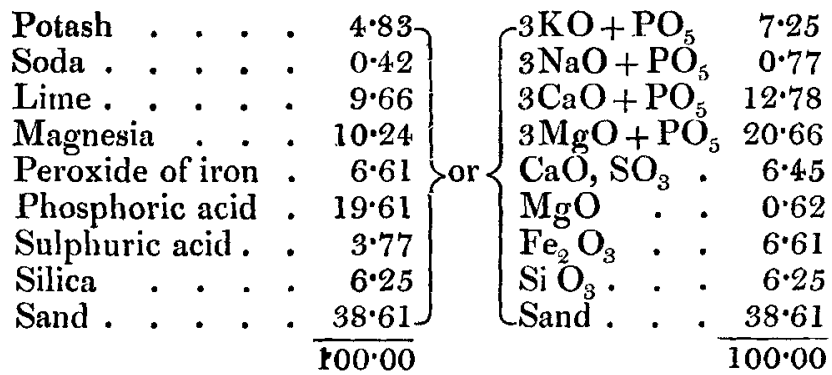

Hence the phosphates of the excrements are c-phosphates, and the bases are all in the proportion of three atoms to one of phosphoric acid. In the aqueous extract, the greater part of the potash is either combined with carbonic acid, or exists in the form of potash; whilst in the excrements themselves, the alkali was combined with an organic substance, which occupied the place of an acid. Since the fæces principally carry off those oxidized salts which are insoluble in water, whilst the urine removes those which are soluble in water, most of the inorganic constituents of the fæces are contained in the muriatic extract of the carbonized mass. 'The large quantity of phosphate of magnesia in this ash is remarkable.

The excrements might be regarded as teleoxidic substances; at least the unoxidized inorganic matters existing in them are so small, that they probably arise merely from the undigested remains of the food. The small quantity of soda present, compared with that of the potash, is also remarkable; especially as the bile principally contains soda, and but little potash. Hence the soda of the bile must be removed by the urine, not the fæces. The following are the inorganic constituents of the fæces as obtained by the three operations :-

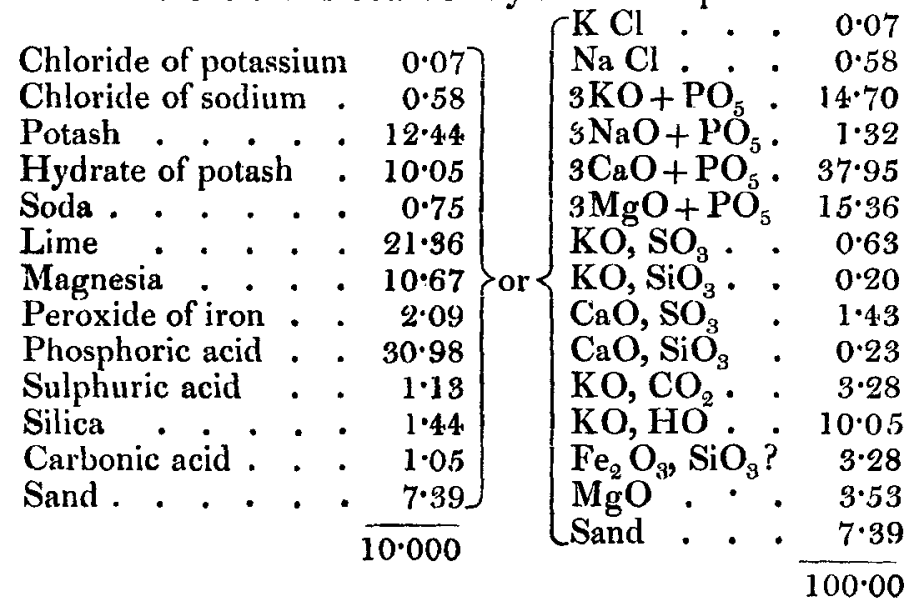


Examination of the Urine.-As the residue of the evaporated urine was very difficult to dry at $212^{\circ} \mathrm{F}$., it was carbonized at once.

Aqueous extract.-This contained by far the greater part of the inorganic constituents of the urine. In the urine excreted during four days, it amounted to no less than $54 \cdot 148 \mathrm{grms}$. These consisted of-

$$
\begin{aligned}
& \text { Chloride of sodium } \quad \text { - } 62 \cdot 78] \quad[\mathrm{NaCl} \cdot \quad \cdot 62 \cdot 78
\end{aligned}
$$

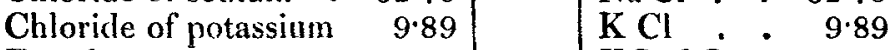

$$
\begin{aligned}
& \text { Potash . . . 15*40 } \mathrm{KO}, \mathrm{SO}_{3} \cdot 5 \cdot 87 \\
& \text { Magnesia . . . } 0.32\} \text { or of }\left\{2 \mathrm{KO}+\mathrm{PO}_{5} \quad 16.12\right. \\
& \text { Phosphoric acid . . } \quad 8.92\} \begin{cases}3 \mathrm{KO}+\mathrm{PO}_{5} & 4.55\end{cases} \\
& \begin{array}{lll}
\text { Sulphuric acid } & \cdot & 2.69 \\
\hline & 2 \mathrm{MgO}+\mathrm{PO}_{5} & 0.42 \\
3 \mathrm{MgO}+\mathrm{PO}_{5} & 0.37
\end{array} \\
& 100 \cdot 00] \quad\left[3 \mathrm{MgO}+\mathrm{PO}_{5} \frac{0.37}{100 \cdot 00}\right.
\end{aligned}
$$

Muriatic extract.-It amounted to 5.085 grms., and consisted of -

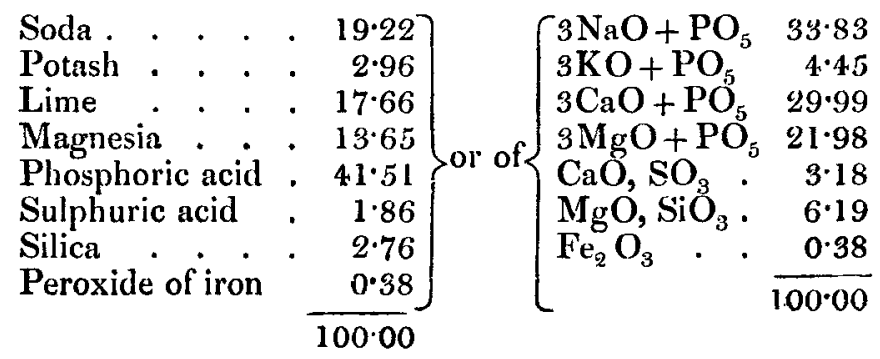

Residuary carbonaceous mass. - This left a very small quantity of ash on incineration, only 0.352 grm., the principal component of which was silica, weighing $0.156 \mathrm{grm}$.; the remainder consisted almost entirely of phosphate of magnesia. It has been suggested above, that this small quantity of inorganic constituents existed in the urine in a perfectly oxidized state, and had resisted the solvent action of the muriatic acid, probably because the magnesia had formed with the silica a compound insoluble in dilute muriatic acid.

If this view be adopted, all the inorganic constituents exist in the urine in a perfectly oxidized state; hence it is a perfectly teleoxidic substance.

The following are therefore the inorganic constituents of the carbonized mass of the evaporated urine :- 
Chloride of sodium . . . . . . 57.03

Chloride of potassium . . . . . . $\quad 8.99$

Tribasic phosphate of soda . . . . 290

Tribasic phosphate of potash . . . 4.53

Bibasic phosphate of potash . . . . 4.65

Tribasic phosphate of lime . . . . 2.57

Tribasic phosphate of magnesia . . 2.57

Bibasic phosphate of magnesia . . . 0.37

Sulphate of potash . . . . . . 5.33

Sulphate of lime. . . . . . . . 0.27

Magnesia, peroxicle of iron, and silica $\quad 0 \cdot 79$

$\overline{100 \cdot 00}$

These inorganic constituents must not be compared with those existing in the urine before carbonization. In the latter the bases are partly combined with organic acids, which are converted into carbonates during the process of carbonization, the carbonic acid of which is expelled by the phosphoric acid of the bibasic phosphates. Thus tribasic phosphates are formed, which cannot exist as such in the urine, because the latter exerts an acid reaction.

During the four days in which the fæces and urine were collected, the inorganic constituents of the former amounted to 10.422 grms., and the latter to 59.58 .5 . This remarkable result would not have been expected $a$ priori. The difference becomes still more striking when the amount of the sand is deducted from the inorganic constituents of the fæces, and which can only be regarded as an accidental mixture.

The following comparison exhibits the inorganic components of the fæces and urine excreted in a day, exclucling the sand :-

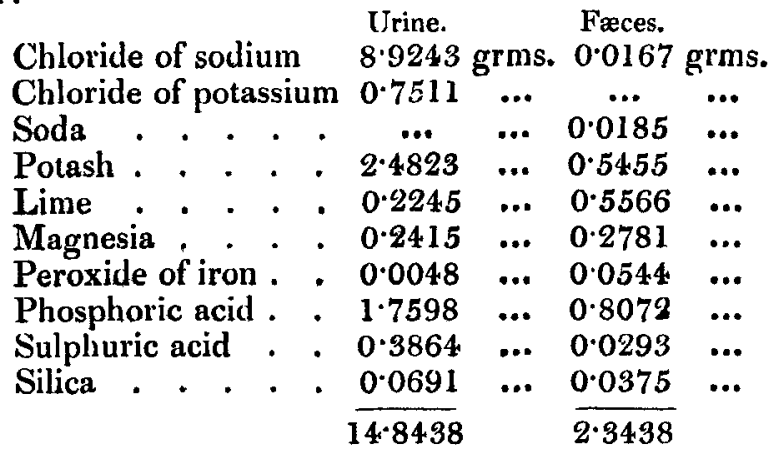

Hence the amount of inorganic constituents in the urine is more than $6 \frac{1}{3}$ times greater than that in the solid excrements. 
The following are the weights of the inorganic constituents obtained in the different parts of the examination of the fæces and the urine :-

Fæces. Urine.

Extracted by water . . . . . . . . 18.55 90.87

Extracted by muriatic acid . . . . . . $62.30 \quad 8.54$

In the ash of the residuary carbonized mass $19.15 \quad 0.59$

Appendix XII.

Examination of the Inorganic Constituents of the Bile (of Oxen). By M. Weidenbusch.

Aqueous extract of the carbonized mass.-This, when evaporated to dryness, consisted of-

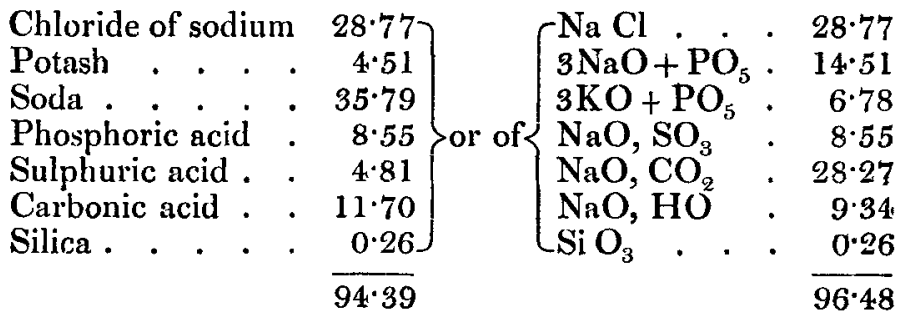

Muriatic extract. - This consisted of-

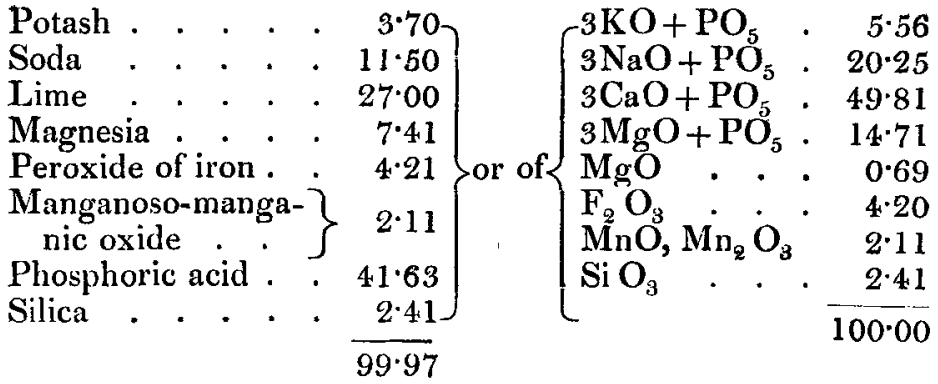

Residuary carbonaceous mass. - The ash consisted of -

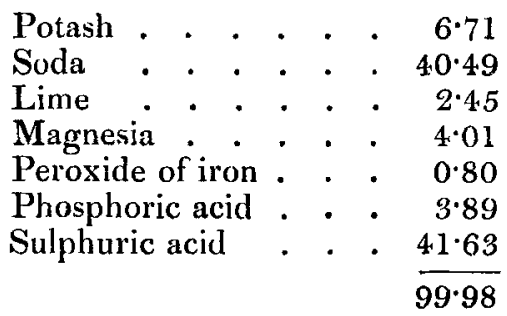


The sulphur may be considered as existing in the carbonized bile, after exhaustion by the solvents, as a constituent of certain compound radicals, in the same manner as was assumed to be the case with the phosphorus in the carbonized product of other organic substances. But in this carbonized mass the amount of sulphur is much larger than would be found by calculation from that of the sulphuric acid obtained. A very large portion of it is volatilized during the oxidation. If the exhausted carbonized mass be mixed with nitrate of baryta, and the mixture be heated to redness, so much sulphate of baryta is obtained, that the quantity of sulphuric acid existing in it amounts to 30 per cent. more than that obtained by the mere oxidation of the carbonized mass.

The following are the proportions of the inorganic components of the bile as obtained in the three operations:-

Extracted by water . . . . . . . . . . 90.85

Extracted by muriatic acid . . . . . . . . 4.93

In the ash of the residue of the carbonaceous mass $\quad 4 \cdot 22$

$100 \cdot 00$

The following are the whole of the inorganic constituents of the bile of the ox:-

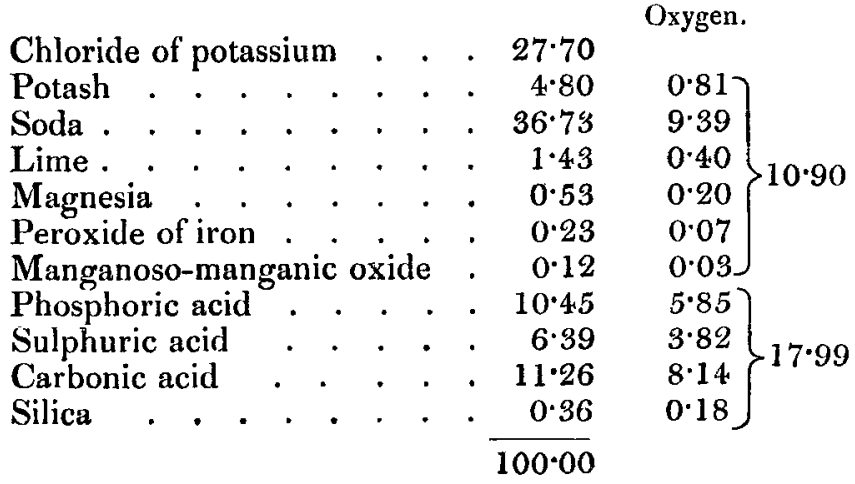

The quantities of the acids are not correct, because, as we have stated, a far larger amount of sulphuric acid would have been obtained had the whole of the sulphur been converted into sulphuric acid.

\section{Appendix XIII.}

Examination of the Inorganic Constituents of Cow's Milk. By M. Weber.

The cows from which the milk was procured were fed with the refuse of a brewery in addition to the ordinary stall-fodder. 
The milk was not skimmed, but evaporated at once and carbonized.

Aqueous extract.-The washing required to be continued for an extraordinary length of time. The residue of the evaporated extract consisted of -

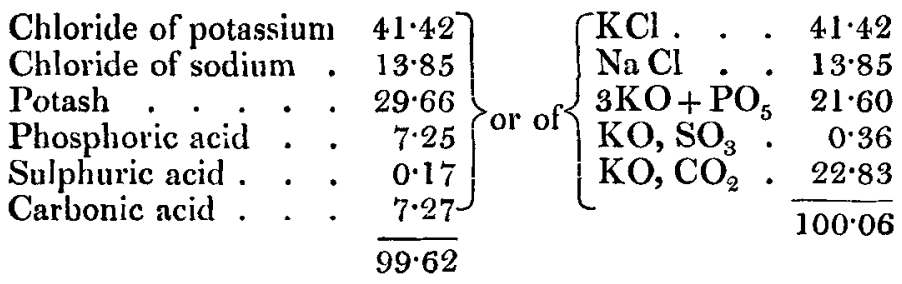

Muriatic extract. - No evolution of carbonic acid could be perceived on the addition of the muriatic acid. The constituents were-

$$
\begin{aligned}
& \text { Potash . . . . . } 6.29 \\
& \text { Soda . . . . . . } 12 \cdot 19 \\
& \text { Lime . . . . . } 3670 \\
& \text { Magnesia . . . } 3.26 \\
& \text { Peruxide of iron . . } 0.30 \\
& \text { Phosphoric acid . . } 41.26 \\
& 100 \cdot 00
\end{aligned}
$$

Hence the muriatic acid had only dissolved phosphates. Residuary carbonaceous mass.-It yielded-

$$
\begin{aligned}
& \text { Potash . . . . } 33.13 \\
& \text { Soda . . . . . } 9.01 \\
& \text { Lime . . . . . . } 16.58 \\
& \text { Magnesia . . . } 340 \\
& \text { Peroxide of iron . . } 1 \cdot 10 \\
& \text { Phosphoric acid . . } 36 \cdot 60 \\
& \text { Silica. . . . . } 0.18 \\
& 100 \cdot 00
\end{aligned}
$$

Thus the anoxidic portion of the milk, after oxidation, was of the same composition as the teleoxidic.

The following are the results of the examination of the milk :-

Extracted by water . . . . . . . . . . $34 \cdot 17$

Extracted by muriatic acid . . . . . . . 31.75

Ash of the remaining carbonaceous mass . . 34.08 
The whole of the constituents were-

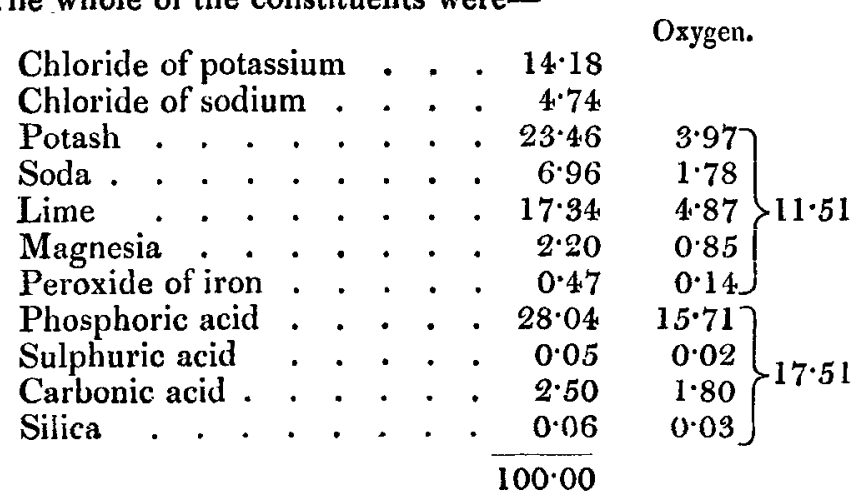

Hence the phosphoric acid of the bases is to that of the acids nearly as $3: 5$. The teleoxidic portion of the milk contains $c$-phosphates, and the anoxidic portion yields by oxidation $c$-phosphates also.

Thus milk is a meroxidic substance. We might almost call it a hemioxidic substance, if the large quantity of the alkaline chlorides contained in the aqueous extract were excluded from the teleoxidic portion, to which they evidently do not belong.

The large amount of phosphoric acid in the teleoxidic portion, and the considerable quantity which the anoxidic portion yields on oxidation, are remarkable. It is hence evident, as has frequently been remarked, how well the milk is adapted for effecting the ossification of the bones in the mammalia.

Whilst in the blood the bases predominate over the acids, in the flesh we find little else than pyrophosphates, and in the milk the bases for the most part form $c$-phosphates.

\section{Appendix XIV. and XV. \\ Examination of the Inorganic Constituents of the White and Yolk of Hen's Eggs. By M. Poleck.}

These experiments were among the first made by the method of carbonization, and were instituted before the process was perfected; they do not therefore deserve too much confidence, although performed with great care. But as they appeared to me of some importance, I shall briefly describe them.

The principal source of error consists in the fact, that in some of the analyses the alkali contained in the muriatic extract, not having been suspected to exist there, was overlooked; moreover, the exhausted carbonized mass being 
burnt in an atmosphere of oxygen, would allow of the volatilization of a considerable.portion of the alkaline phosphates. The separation of the white from the yolk can be easily effected, by well boiling the eggs in water until they become hard.

The relative proportion of the white and yolk was not exactly the same in all the eggs. The following results were obtained in regard to this point:-

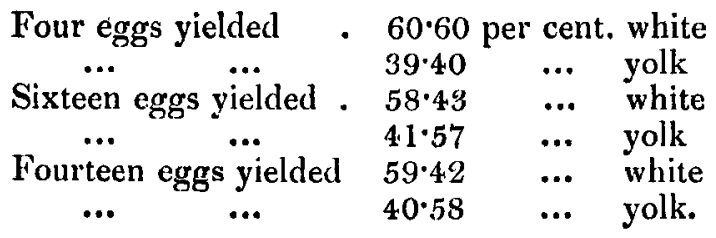

White of egg.-It yielded in two instances-

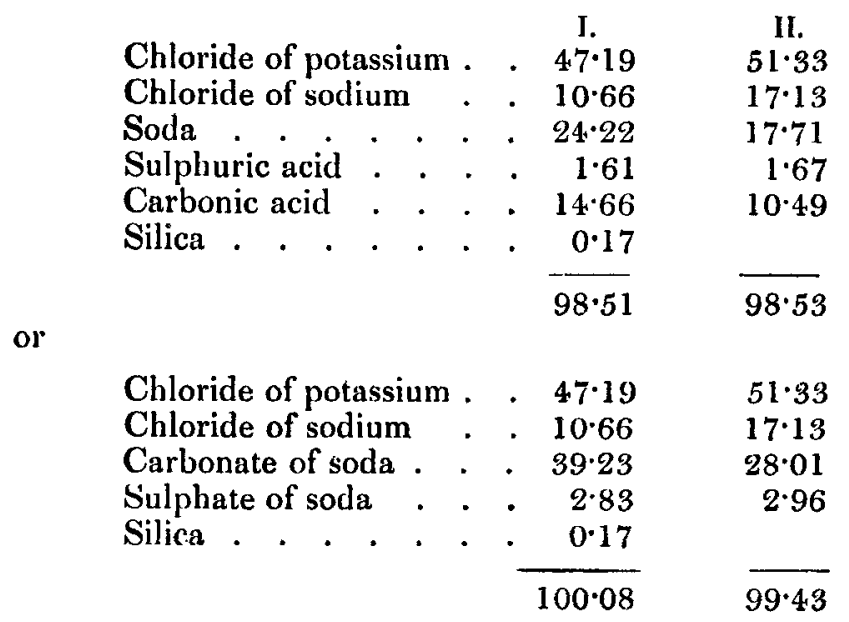

In both analyses a little more carbonic acid was found than could be combined with the alkali. This is remarkable; because in the aqueous extracts of the carbonized mass of other organic substances, considerably less carbonic acid was frequently found than was requisite for the saturation of the alkali, a considerable portion of the carbonic acid being frequently reduced to carbonic oxide by the carbon.

Muriatic extract.-As in the first experiment, the presence of the alkalies was overlooked; the result of the second only is given :- 


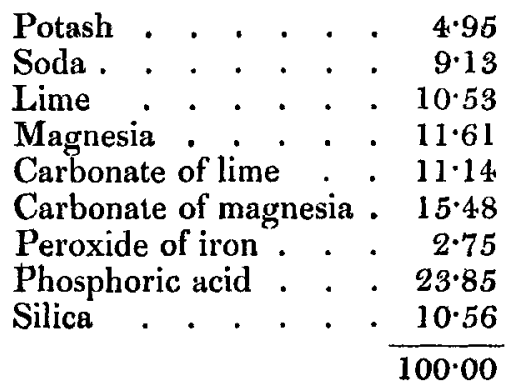

Residuary carbonaceous mass.-It was not incinerated with platinum, but in oxygen gas; hence there was a loss. I have already remarked that the proteine substances of vegetables and animals alone appear to be meroxidic bodies; all others appear to be of a teleoxidic nature. The white of hen's eggs, however, forms a remarkable exception to all the other proteine substances which have been examined, in consequence of the very small quantity of anoxidic substance which it contains. The amount of ash is very small. In both experiments the charred mass contained silica in the form of sand, which, however, was deducted from the ash. The following was the composition of the two ashes :-

I.

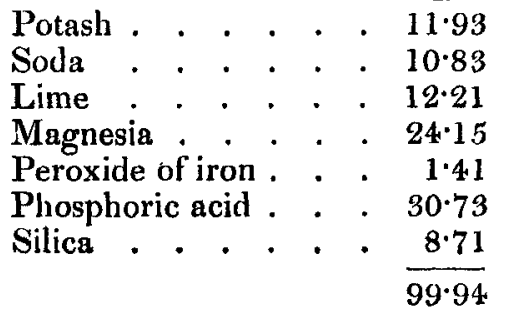

II.

$16 \cdot 76$

$5 \cdot 4.8$

$8 \cdot 21$

$9 \cdot 02$

$5 \cdot 64$

$37 \cdot 24$

$17 \cdot 63$

$\overline{99 \cdot 98}$

These tesults differ very considerably; the cause must be determined by future experiments.

On arranging the constituents in the form of salts, we find in the first experiment $b$-phosphoric acid and some very basic silicates; in the second only $b$-phosphoric acid and less basic silicates.

The quantities obtained were-

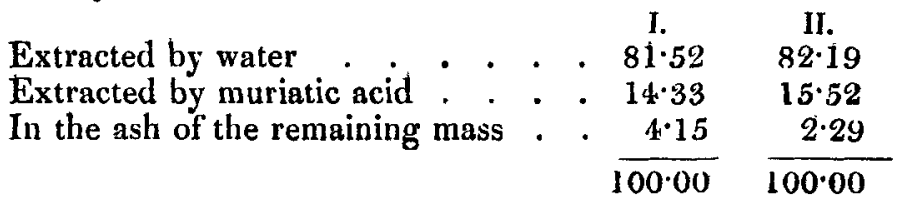


The components of the subject of the socond analysis, as obtained in the three operations, were-r

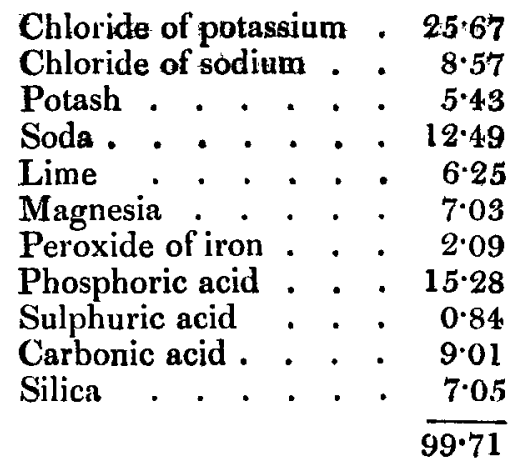

In accordance with these investigations, the white of hen's eggs, although decidedly a proteine substance, must be enumerated amongst the almost teleoxidic substances. The large quantity of silica in the white of egg, both in the teleoxidic and the anoxidic portion, is remarkable. The white of birds' eggs is equally as requisite for the formation of the feathers, which, according to recent investigations, contain a large amount of silica, as the milk of the mammalia is for the production of the bones.

\section{Yolk of Egg.}

Aqueous extract.-It exerted a strongly acid reaction upon litmus paper, and contained a considerable quantity of the earthy phosphates in solution, which were not on this occasion separated, but added to the muriatic extract. The dry mass fused into a transparent vitreous mass at a low red beat. It consisted of -

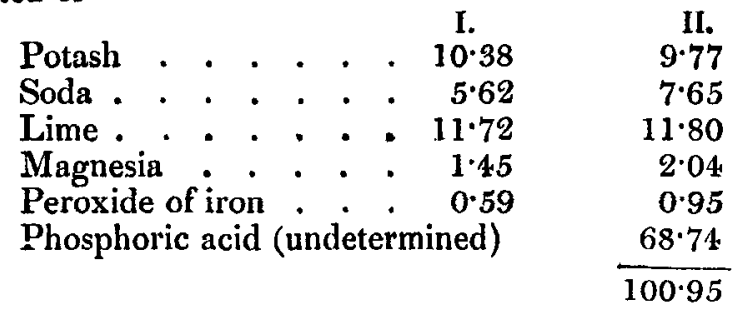

The phosphoric acid formed metaphosphates with the bases, excepting with the peroxide of iron. In the extract itself, they did not exist in this form, but in that of acid b-phosphates, for it strongly reddened litmus paper; they were, however, contained in that state in the solution of the fused residue of 
the evaporated mass. In accordance with the second experiment, we obtain the following arrangement for the salts:-

$$
\begin{aligned}
& \text { Monobasic phosphate of potash - 24.57 } \\
& \text { Monobasic phosphate of soda . . 25.16 } \\
& \text { Monobasic phosphate of lime . . } 41.73 \\
& \text { Monobasic phosphate of magnesia } \quad 9.08 \\
& \text { Perphosphate of iron . . . . } 1.79 \\
& \overline{102 \cdot 33}
\end{aligned}
$$

The calculated amount of phosphoric acid is 70.18 per cent.; experiment gave 68.74 per cent.

Muriatic extract.-The following is the composition of that of the second experiment:-

$$
\begin{aligned}
& \text { Lime . . . . . . } 22.32 \\
& \text { Magnesia . . . , } 2.98 \\
& \text { Peroxide of iron . . } 3.71 \\
& \text { Phosphoric acid . . } \frac{70.97}{99.98}
\end{aligned}
$$

These salts are also metaphosphates, the iron compound probably being excepted. They correspond to-

$$
\begin{aligned}
& \text { Monobasic phosphate of lime . . 78.94 } \\
& \text { Monobasic phosphate of magnesin . } 13.30 \\
& 2 \mathrm{Fe}_{2} \mathrm{O}_{3}, 3 \mathrm{PO}_{5} \cdot . \cdot . \cdot . \quad . \quad 8 \cdot 66 \\
& \overline{100 \cdot 90}
\end{aligned}
$$

The calculated amount of phosphoric acid would be 71.89 per cent.; that found was 70.97 per cent.

Residuary carbonaceous mass. - This, like the white of egg, was also burnt in oxygen gas. Hence the results obtained in the two experiments differ; in the first much less ash was found than in the second. The latter consisted of-

$$
\begin{aligned}
& \text { Potash . . . . . . } 7.96 \\
& \text { Soda . . . . . . 6.75 } \\
& \text { Lime . . . . . . } 13.04 \\
& \text { Magnesia . . . . 2.04 } \\
& \text { Peroxide of iron . . . } 0.99 \\
& \text { Phosphoric acid . . 64.13 } \\
& \text { Silica . . . . . } 276 \\
& \overline{97 \cdot 67}
\end{aligned}
$$

These are also mostly metaphosphates; only a very small quantity of the bases can be combined with pyrophosphoric acid. 
The following are the results of the experiments :-

$$
\begin{aligned}
& \text { I. II. }
\end{aligned}
$$

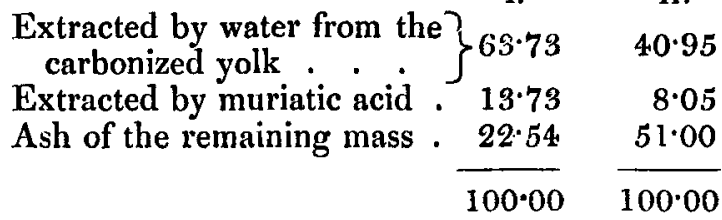

These results differ very considerably, yet they show that the yolk undoubtedly belongs to the meroxidic substances.

The inorganic constituents of the entire mass of the carbonized yolk in the second experiment were-

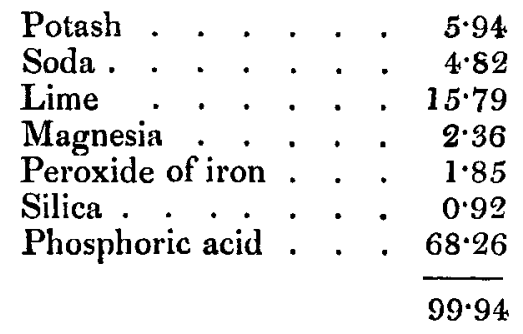

These are metaphosphates. The yolk of egg contains more phosphoric acid than any other organic substance treated of in this memoir.

\section{Inorganic Constituents of Yeast (from Berlin Pale Beer). By B. W. Bull of Nere York.}

The yeast was washed with distilled water; the washing cannot however be perfectly effected, because the pores of the filter become so readily stopped up.

Aqueous extract.-This did not affect litmus paper; during evaporation it deposited earthy phosphates, which were added to the muriatic extract. It consisted of-

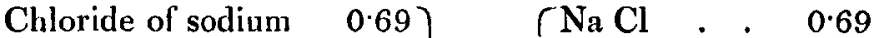

$$
\begin{aligned}
& \text { Potash . . . . } 45 \cdot 79\} \text { or of } 4 \mathrm{KO}+\mathrm{PO}_{5} \quad 40 \cdot 18
\end{aligned}
$$

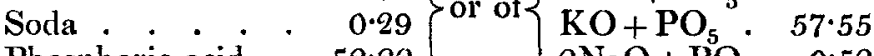

$$
\begin{aligned}
& \text { Phosphoric acid . 52.22 } \quad\left[\begin{array}{ll}
2 \mathrm{NaO}+\mathrm{PO}_{5} & 0.52
\end{array}\right. \\
& 98.99 \quad 98 \cdot 94
\end{aligned}
$$

Hence the aqueaus extract consisted essentially of $a$ and $b$. phosphate of potash. 
Muriatic extract.-It was composed of-

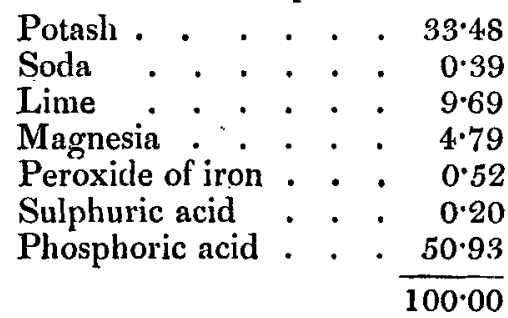

Part of the phosphoric acid is combined with the bases in the form of $b$ - and part in that of $a$-phosphates. It is not easy to explain why these are not extracted from the carbonized mass with the other $a$-phosphates by water. The calculated salts are-

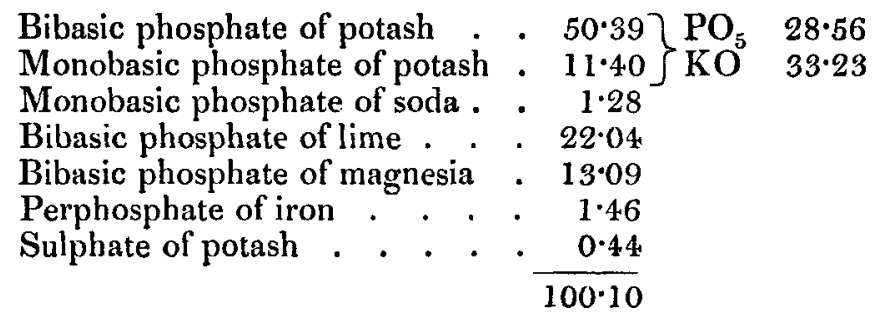

Residuary carbonized mass.-This consisted of-

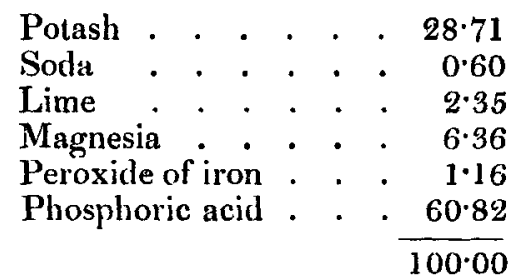

or

\begin{tabular}{|c|c|}
\hline Monobasic plosphate of potash & $72 \cdot 14\left\{\begin{array}{l}\mathrm{PO}_{5} \\
\mathrm{KO}\end{array}\right.$ \\
\hline $\begin{array}{l}\text { Monobasic phosphate of soda } \\
\text { Bibasic phosphate of magnesia } \\
\text { Monobasic phosphate of magnesia } \\
\text { Phosphate of lime }\left(8 \mathrm{CaO}, 3 \mathrm{P} \mathrm{O}_{5}\right) \\
\text { Perphosphate of iron }\end{array}$ & $\begin{array}{r}1 \cdot 97 \\
13 \cdot 91 \\
5 \cdot 18 \\
4 \cdot 60 \\
2 \cdot 20\end{array}$ \\
\hline
\end{tabular}

The phosphate of lime is in this case assumed as having the same composition as that precipitated from the muriatic solution by ammonia. 


\section{On the Development of Electricityby Muscular Contraction.}

The entire results of the experiments were-

Extracted by water . . . . . . . . . 27.24

Extracted by muriatic acid . . . . . . 3770

In the ash of the residuary carbonaceous mass 35.06

The whole constituents were-

$\overline{100 \cdot 00}$

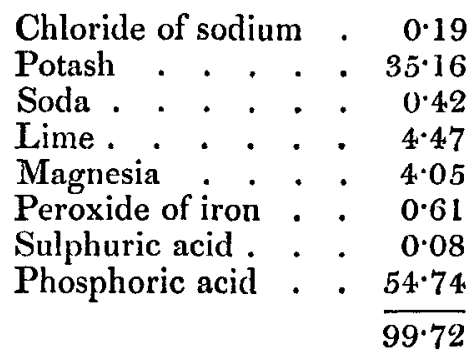

These results agree very well with those obtained by Mitscherlich.

Yeast is therefore a meroxidic substance, and possesses most analogy with flesh in regard to its inorganic constituents.

XXXVI. Notice respecting Du Bois Reymond's Discovery of the Development of Electricity by Muscular Contraction. $B y$ Prof. Buff of Giessen*.

THE remarkable observation made by Du Bois Reymond, 1 that an electric current can be excited by muscular contraction, has been called in question by Messrs. Despretz and Becquerel, who did not succeed in obtaining favourable results on repeating the experiment $\uparrow$. Under these circumstances it may prove of interest to describe a few experiments which I have made with a better result.

The galvanometer employed was constructed by Kleiner of Berlin; it had 3000 convolutions of a copper wire one-fifth of a millimetre in thickness. 'The extremities of this wire were connected, according to Du Bois Reymond's directions, with strips of platina cut out of the same sheet of metal. Each strip dipped permanently into a vessel containing a saturated solution of common salt. Notwithstanding this precaution it was found impossible to obtain an absolute and permanent uniformity of the two strips. However, on immersing the fingers in the salt water, in general only a faint current, which

* From Liebig's Annalen der Chimie for June 1849.

+ A notice of M. Du Bois Reymond's experiments appeared in the Philosophical Magazine for July 1849, p. 543; Messrs. Becquerel and Despretz's observations on the same subject will be found at pp. 53, 55 of the present volume.-Ev. Phil. Mag. 